\title{
Radiologie zum Ausprobieren: X-perimente gehen auf Tour
}

Zum Röntgenjahr 2020 geht ein ganz besonderer Bus auf Tour: Das „X-perimente-Mobil“ hat interaktive Experimente an Bord und wird Schulen, Museen und Bildungseinrichtungen in ganz Deutschland besuchen.

Gleich zwei Jubiläen machen das Jahr 2020 zum „Röntgenjahr“: 125 Jahre sind seit der Entdeckung der Röntgenstrahlen vergangen und ihr Entdecker Wilhelm Conrad Röntgen hätte seinen 175. Geburtstag gefeiert. Das Deutsche Röntgen-Museum in Remscheid und die Reiss-Engelhorn-Museen in Mannheim feiern diese Ereignisse mit dem Projekt „X-perimente - Das Unsichtbare sichtbar machen“. Ein umgebauter Sprinter ist ab Januar als rollendes Experimentierlabor unterwegs zu Schülerinnen und Schülern, um in ihnen mit Hilfe von Röntgentechnologie die Begeisterung für Naturwissenschaften und Medizin zu wecken.

\section{Experimentieren wie Röntgen}

Die Versuche richten sich an Kinder und Jugendliche von der Grundschule bis zur Oberstufe. Ganz im Sinne des Physikers und Tüftlers Röntgen sollen die Mädchen und Jungen selbst zu Entdeckern werden, Vorhandenes hinterfragen und spielerisch Neues entwickeln. Die Versuche im Experimentier-Mobil vermitteln unterschiedliche Techniken, mit denen das „Innere“ von Dingen sichtbar gemacht werden kann: vom langwelligen infrarotem Licht bis hin zu den kurzwelligen Gammastrahlen und dem Ultraschall.

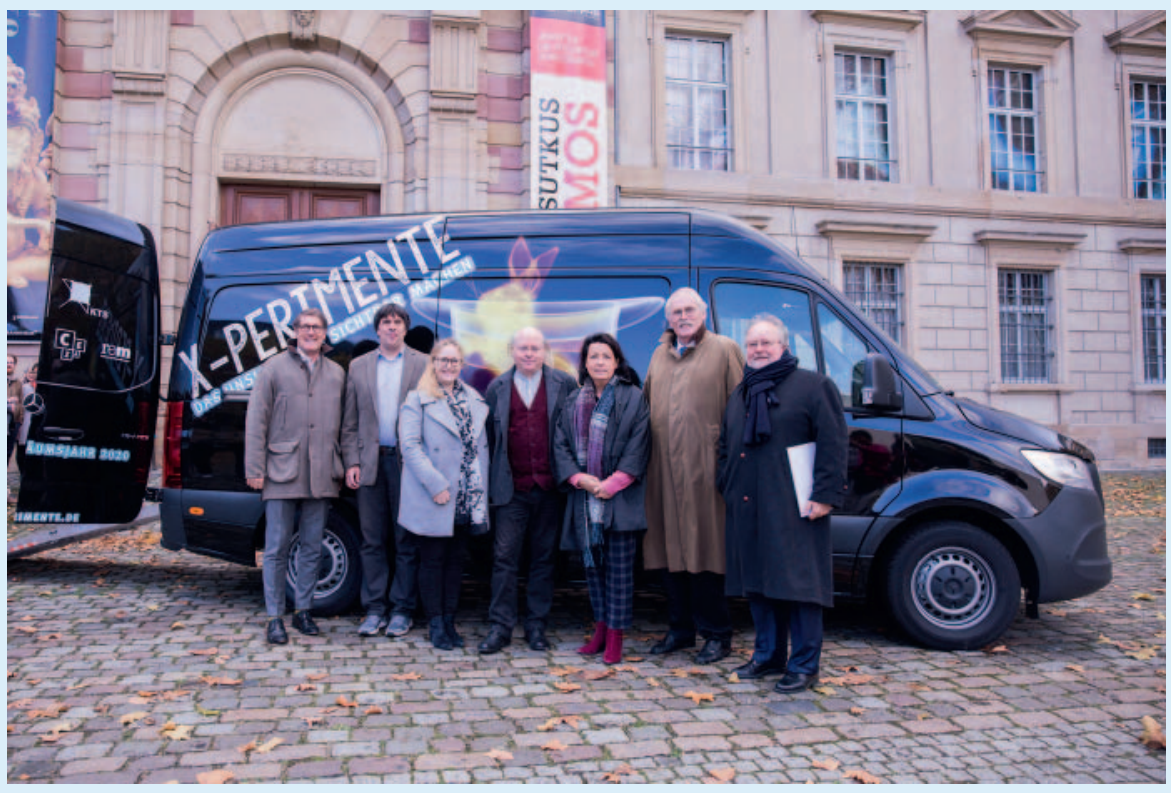

Die X-perimente-Kooperationspartner (v. I. n. r.): Bürgermeister Michael Grötsch, Dr. Jens-Peter Knemeyer und Prof. Dr. Nicole Marmé (Pädagogische Hochschule Heidelberg), Prof. Dr. Wilfried Rosendahl (Direktor Reiss-Engelhorn-Museen Mannheim und Projektleiter), Beate Spiegel (Geschäftsführerin Klaus Tschira Stiftung), Karl-Heinz Humpert (Kulturausschussvorsitzender der Stadt Remscheid) sowie Prof. Dr. Alfried Wieczorek (Generaldirektor der Reiss-EngelhornMuseen). Foto: Maria Schumann.

\section{Fachkundige Umsetzung}

Das Projekt wird durch die Klaus Tschira Stiftung ermöglicht. Sie fördert dessen Entwicklung und Umsetzung mit rund 700000 Euro. Das pädagogische Konzept erarbeitete die Arbeitsgruppe didaktik-aktuell der Pädagogischen Hochschule Heidelberg in Kooperation mit der Leitung des Röntgen-Schülerlabors im Röntgen-Museum sowie den Wissenschaftlern und Museumspädagogen der Reiss-Engelhorn Museen.
Weitere Informationen finden Sie auf der Webseite der Klaus Tschira Stiftung www.klaus-tschira-stiftung.de/ sowie auf www.x-perimente.de. 